\title{
Glomerular angiotensinogen is induced in mesangial cells in diabetic rats via reactive oxygen species-ERK/JNK pathways
}

\author{
Naro Ohashi, Maki Urushihara, Ryousuke Satou and Hiroyuki Kobori
}

Whereas intra-renal angiotensinogen is predominantly localized in proximal tubular cells under basal conditions, it has been previously reported that angiotensinogen expression is induced in glomeruli under pathological conditions. However, there is no detailed information regarding the mechanism of the induced glomerular angiotensinogen. We used genetic pairs of Zucker diabetic fatty (ZDF) obese and lean rats to determine glomerular angiotensinogen expression. The levels of glomerular angiotensinogen immunoreactivity in ZDF obese rats were higher than those in ZDF lean rats. Double staining by IHC or IF with angiotensinogen and Thy 1.1 antibodies showed that the majority of angiotensinogen in glomeruli was seen in mesangial cells. The levels of glomerular immunoreactivity for 4-HNE and urinary excretion of 8-isoprostane-markers of ROS-in ZDF obese rats were higher than those in ZDF lean rats. To confirm this system, primary rat mesangial cells were treated with hydrogen peroxide $\left(\mathrm{H}_{2} \mathrm{O}_{2}\right)$ to clarify the signal transduction pathway for glomerular angiotensinogen expression. $\mathrm{H}_{2} \mathrm{O}_{2}$ induced an increase in angiotensinogen expression in a dose- and time-dependent manner, and the $\mathrm{H}_{2} \mathrm{O}_{2}$-induced upregulation of angiotensinogen was suppressed by catalase. Furthermore, the $\mathrm{H}_{2} \mathrm{O}_{2}$-induced upregulation of angiotensinogen was inhibited by a mitogenactivated protein kinase (MAPK) kinase (MEK) inhibitor and a c-Jun N-terminal kinase (JNK) inhibitor, but not inhibited by a p38 MAPK inhibitor. These data suggest that the majority of angiotensinogen was induced in mesangial cells in glomeruli under pathological conditions such as diabetic nephropathy, and angiotensinogen expression in mesangial cells was mediated by $\mathrm{H}_{2} \mathrm{O}_{2}$ and the subsequent activation of extracellular-regulated kinase (ERK)/JNK pathways.

Hypertension Research (2010) 33, 1174-1181; doi:10.1038/hr.2010.143; published online 5 August 2010

Keywords: glomerular angiotensinogen; hydrogen peroxide; mesangial cells; mitogen-activated protein kinase pathways; Zucker diabetic fatty rat

\section{INTRODUCTION}

The intra-renal renin-angiotensin system (RAS) has a crucial role in the regulation of renal function and the pathophysiology of hypertension. ${ }^{1,2}$ Activation of the intra-renal RAS was reported in several animal models of hypertension and kidney disease. ${ }^{3-6}$ Angiotensinogen (AGT) is the only known substrate for renin, which is the ratelimiting enzyme of the RAS. ${ }^{7}$ In the normal kidney, both AGT mRNA and protein are mainly expressed in the proximal tubules, and only small amounts are present in the glomeruli. ${ }^{8-11}$ We have previously reported weak positive staining of AGT in glomerular endothelial cells in normal kidneys. ${ }^{12}$ In addition, we have reported significantly high AGT expression in the glomeruli in IgA nephropathy patients compared with that in control subjects. ${ }^{13}$ However, glomerular cells that express AGT mainly under pathophysiological conditions have not been identified.

It has been reported that angiotensin-II (Ang-II) upregulates AGT expression in immortalized rat proximal tubular cells, ${ }^{14}$ and that exposure to high glucose induces AGT expression in primary rat mesangial cells. ${ }^{15,16}$ However, the stimulus that induces AGT expression in individual cells in the glomerulus has not been confirmed.

The signal transduction pathways involved in AGT expression are currently being investigated. We have recently reported that in immortalized human renal proximal tubular epithelial cells, Ang-II acts synergistically with interleukin-6 to increase AGT expression through activation of nuclear factor- $\mathrm{KB}$ and the signal transducer and activator of transcription-3. ${ }^{17}$ It has also been reported that in immortalized rat proximal tubular cells, a high glucose concentration stimulates AGT expression through reactive oxygen species (ROS) generation and subsequent p38 mitogen-activated protein kinase (MAPK) expression. ${ }^{18}$ However, the signal transduction pathway that induces AGT expression has not been completely elucidated yet.

Thus, this study was performed to clarify whether AGT expression in the glomeruli increases in diseased kidneys and to identify the glomerular cells that express the majority of AGT. We have also 
attempted to identify the stimuli that induce AGT expression in individual cells in the glomerulus and the signal transduction pathway associated with glomerular AGT expression.

\section{METHODS}

\section{Experimental animals}

The experimental protocol was approved by the Institutional Animal Care and Use Committee of Tulane University. Genetic pairs of male Zucker diabetic fatty (ZDF) obese rats (ZDF/GmiCrl-falfa) and age-matched control ZDF lean rats $(\mathrm{ZDF} / \mathrm{GmiCrl}-+/ f a)$ were purchased from Charles River Laboratories (Wilmington, MA, USA) and maintained as described previously. ${ }^{19}$ Because it was previously reported that AGT expression in the cortex increases at week $18,{ }^{19}$ the rats were killed at week 18 in this study.

\section{Primary culture of rat mesangial cells}

Mesangial cells were cultured by standard techniques using glomerular isolation with different sieves. ${ }^{20-22}$ Mesangial cells were maintained and used between passage- 5 and 9 as described previously. ${ }^{20-22}$

\section{Study design for the cell experiments}

For the RNA experiments, mesangial cells were plated and were treated with hydrogen peroxide $\left(\mathrm{H}_{2} \mathrm{O}_{2}\right)$ (Fisher Science, Pittsburgh, PA, USA) at the indicated concentration. To confirm the influence of $\mathrm{H}_{2} \mathrm{O}_{2}$ on AGT expression, mesangial cells were co-treated with $300 \mathrm{U} \mathrm{ml}^{-1}$ catalase (Sigma, St Louis, MO, USA) as described previously. ${ }^{18}$ To examine the signal transduction pathway involved in AGT expression induced by $\mathrm{H}_{2} \mathrm{O}_{2}$ treatment, mesangial cells were treated with a specific MAPK kinase (MEK) inhibitor (U0126) (Sigma), a c-Jun $\mathrm{N}$-terminal kinase (JNK) inhibitor (SP600125) (Sigma) or a p38 MAPK inhibitor (SB203580) (Calbiochem, Madison, WI, USA) as described previously. ${ }^{23}$

Cell lysates and supernatants were collected in a similar manner to the RNA experiments. Every hour, $5 \times 10^{-5} \mathrm{M} \mathrm{H}_{2} \mathrm{O}_{2}$ was added and the supernatants were collected at 0,4 and $7 \mathrm{~h}$. To collect cell lysates, $10^{-4} \mathrm{M} \mathrm{H}_{2} \mathrm{O}_{2}$ was added and the lysates were harvested at $0,5,10$ and $15 \mathrm{~min}$.

\section{Evaluation of glomerular AGT expression}

Kidney tissues were fixed in zinc-saturated formalin and embedded in paraffin, and 3- $\mu \mathrm{m}$-thick tissue sections were prepared. To examine the expression levels of glomerular AGT, immunohistochemical analysis of AGT was performed with a rabbit polyclonal anti-mouse/rat AGT antibody (Immuno-Biological Laboratories Co. Ltd, Takasaki, Japan), using a robotic system (Autostainer; DakoCytomation, Glostrup, Denmark), and was counterstained with hematoxylin. Twenty glomeruli were examined for each rat and the intensity of AGT immunoreactivity (brown) corrected for the size of glomeruli was calculated using the Image-Pro Plus software (Media Cybernetics, Bethesda, MD, USA). Thereafter, the average intensity of AGT immunoreactivity was calculated for each rat. ${ }^{24}$

\section{Double staining by IHC}

Double staining by immunohistochemistry (IHC) using anti-AGT and Thyl.1 (a specific marker for mesangial cells) antibodies was performed using the DakoCytomation Envision Doublestain System (DakoCytomation). First, the kidney tissues were stained with a mouse monoclonal anti-rat Thy1.1 antibody (Serotec, Kidlington, UK), using 3,3'-diaminobenzidine (brown); after this, they were stained with the anti-AGT antibody, by using Fast Red (red).

\section{Double staining by IF}

Frozen sections of $3 \mu \mathrm{m}$ thickness were prepared and double staining was performed using anti-AGT antibody with either an anti-Thyl.1 antibody or a mouse monoclonal anti-rat synaptopodin (a specific marker of glomerular epithelial cells) antibody (Progen Biotechnik, Heidelberg, Germany). The sections were incubated with an Alexa Fluor-594-labeled secondary antibody (Molecular Probes, Eugene, OR, USA) for the anti-AGT antibody and an Alexa Fluor-488-labeled secondary antibody (Molecular Probes) for the anti-Thy1.1 antibody and anti-synaptopodin antibody. Renal localization of AGT was investigated with an immunofluorescence (IF) microscope (BX51; Olympus, Tokyo, Japan).

\section{Evaluation of glomerular 4-HNE expression}

The intensity of 4-hydroxy-2-nonenal (4-HNE), which is a marker of oxidative stress, ${ }^{25}$ in the glomeruli was examined by IHC using a mouse monoclonal anti-4-HNE antibody (Japan Institute for the Control of Aging, Fukuroi, Japan) as previously described. ${ }^{5,13,24}$

\section{Urinary protein and 8-isoprostane measurements}

Before killing, 24-h urine samples were collected at week 18. Urinary protein excretion was measured by colorimetric assays (Bio-Rad, Hercules, CA, USA). As a marker of oxidative stress, 8-isoprostane-the major urinary metabolite of F2-isoprostanes-was used. ${ }^{26}$ It is reported that 8-isoprostanes is synthesized by mesangial cells in the ambient high-glucose condition..$^{27}$ We therefore measured its urinary concentrations as described previously. ${ }^{19}$

\section{Quantitative real-time RT-PCR}

AGT mRNA expression in the rat mesangial cells was evaluated by quantitative real-time RT-PCR (qRT-PCR) performed using the TaqMan PCR system (Applied Biosystems Inc., Foster City, CA, USA) as described previously. 5,17 The data were normalized by the expression levels of rat $\beta$-actin mRNA. The following probes and primers were used: AGT: forward primer, $5^{\prime}$-GAAGATG AACTTGCCACTAGA-3'; reverse primer, 5'-AAGTGAACGTAGGTGTTGAA A-3'; and probe, 5'/6-FAM/CAGCACGGACAGCACCCTATT/BHQ1/3'; $\beta$-Actin: forward primer, $5^{\prime}$-ATCATGAAGTGTGACGTTGA-3'; reverse primer, $5^{\prime}$-GAT CTTCATGGTGCTAGGAGC- $3^{\prime}$; and probe, 5'/HEX/TCTATGCCAACACAGTG CTGTCTGGT/BHQ2/3'.

\section{Western blot analysis}

AGT was secreted in culture media but not found in cell lysates, as described previously. ${ }^{28}$ Therefore, the same numbers of cells were plated and maintained under the same conditions in each well. Thereafter, the supernatants from the culture medium were concentrated using a Microcon Centrifugal Filter Device (Millipore, Billerica, MA, USA). To detect the levels of phosphorylation of extracellular-regulated kinase (ERK), p38 MAPK and JNK in the cell lysates, the cells were harvested. Thereafter, western blot analysis was performed as described previously using the Odyssey System (Li-Cor Biosciences, Lincoln, $\mathrm{NE}, \mathrm{USA}) .{ }^{17} \mathrm{~A}$ rabbit polyclonal anti-mouse/rat AGT antibody (ImmunoBiological Laboratories) was used for rat AGT detection. Mouse monoclonal anti-phospho-ERK, anti-phospho-p38 MAPK and anti-phospho-JNK antibodies (Cell Signaling, Danvers, MA, USA) were used for detection of phosphorylation of ERK, p38 MAPK and JNK. Thereafter, the phosphorylation levels were normalized using rabbit polyclonal anti-total-ERK, anti-total-p38 MAPK and anti-total-JNK antibodies (Cell Signaling), respectively.

\section{Statistical analysis}

The differences among the groups with respect to various parameters were evaluated using analysis of variance. Statistical analysis was performed with the StatView software (Abacus Concepts Inc., Berkeley, CA, USA). All the data are presented as the mean \pm s.d. $P<0.05$ was considered statistically significant.

\section{RESULTS}

Increase of urinary protein excretion and induction of AGT expression in the glomeruli of ZDF obese rats

To evaluate the glomerular disease of ZDF obese rats, urinary protein excretion was measured. Urinary protein excretion of ZDF obese rats was significantly higher than that of ZDF lean rats (ZDF obese rats, $22.1 \pm 2.7 \mathrm{mg} \mathrm{day}^{-1}$ versus $\mathrm{ZDF}$ lean rats, $6.8 \pm 0.6 \mathrm{mg} \mathrm{day}^{-1}$, $P<0.01$ ).

The kidney tissues of ZDF lean and obese rats were immunohistochemically analyzed for AGT. As indicated by the arrows, it seems likely that the majority of glomerular AGT staining was found in mesangial cells. AGT immunoreactivity in the glomeruli of ZDF obese 
rat was significantly increased compared with that of ZDF lean rat (Figure 1A).

\section{Regions showing AGT expression in the glomerulus}

To confirm AGT expression in the mesangial cells in the glomeruli, we performed double staining by IHC with anti-AGT and Thyl.1 antibodies. It was confirmed that the majority of glomerular AGT was expressed in mesangial cells, as indicated by the arrows. However, as indicated by the asterisk, there was some minor staining that was observed in cells other than mesangial cells and there was a possibility that they were localized in podocytes (Figure 1B). To detect the regions of glomerular AGT expression more clearly, we performed double staining by IF using an anti-AGT antibody with either an anti-Thy1.1 antibody or an anti-synaptopodin antibody. Merged regions between the anti-AGT antibody and anti-Thyl.1 antibody were much larger than those between the anti-AGT antibody and anti-synaptopodin antibody. This result shows that AGT was expressed more largely in mesangial cells than in glomerular epithelial cells (Figure 1C).

\section{Induction of ROS in ZDF obese rats}

The intensity of immunoreactivity for 4-HNE was monitored in the glomerulus in ZDF lean and obese rats. It was remarkably high in ZDF obese rats compared with that in the ZDF lean rats (Figure 1D). In addition, urinary excretion of 8-isoprostane was significantly high in the $\mathrm{ZDF}$ obese rats compared with that in the ZDF lean rats (Figure 1E).

\section{Augmentation of AGT mRNA expression by $\mathrm{H}_{2} \mathrm{O}_{2}$ treatment}

Primary rat mesangial cells were treated with $\mathrm{H}_{2} \mathrm{O}_{2}$ to examine the effect of ROS on AGT mRNA expression. The AGT mRNA expression

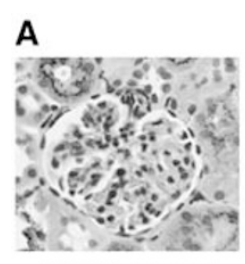

ZDF lean rat

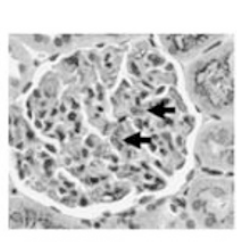

ZDF obese rat
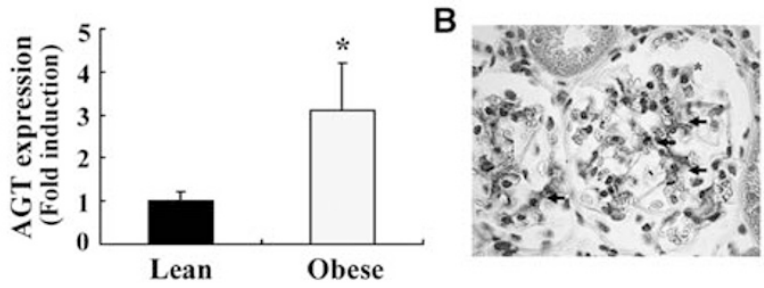
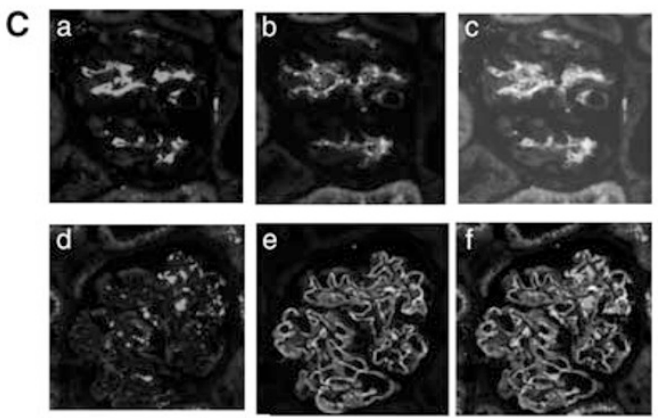

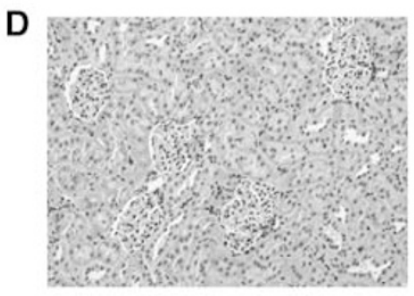

ZDF lean rat

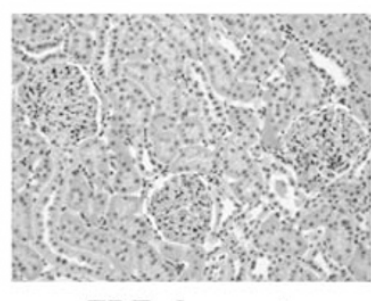

ZDF obese rat

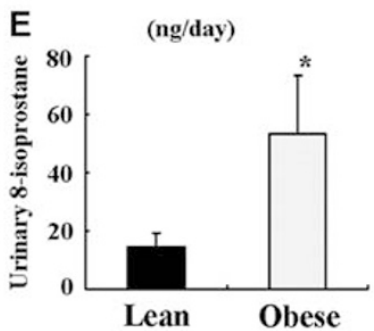

Figure 1 (A) Comparison of glomerular AGT expression levels between ZDF lean rats and ZDF obese rats at week 18. Representative photomicrographs of immunoreactivity for glomerular AGT in ZDF lean rats and ZDF obese rats at week 18 . As the arrows indicate, it seems likely that the majority of glomerular AGT was expressed in mesangial cells. The immunoreactivity for glomerular AGT in ZDF obese rats was remarkably increased compared with that in ZDF lean rats. Original magnification: $\times 400$. Semi-quantitative analysis of intensity of glomerular AGT immunoreactivity corrected for the size of glomeruli in ZDF lean rats and ZDF obese rats at week 18. Twenty glomeruli were examined for each rat and the averaged intensities of AGT immunoreactivity corrected for the size of glomeruli were obtained for each rat. The ratio was calculated relative to ZDF lean rat. ${ }^{*} P<0.05$ vs. ZDF lean rat. (B) Regions of glomerular AGT expression in ZDF obese rats as observed by immunohistochemical double staining. Representative photomicrograph of ZDF obese rats at week 18. Double staining was performed by IHC with an anti-AGT antibody (red) and an anti-Thy1.1 (a specific marker for mesangial cells) antibody (brown). As the arrows show, the majority of mesangial cells were double-stained. Conversely, as the asterisk shows, there was some minor staining that was observed in cells other than mesangial cells. Original magnification: $\times 400$. (C) Regions of glomerular AGT expression in ZDF obese rats as observed by IF. Representative photomicrographs of ZDF obese rats at week 18 by IF. IF staining of AGT (red; a, d) was performed with either a mesangial cell marker-Thy1.1 (green; b) or a glomerular epithelial cell marker-synaptopodin (green; e). The merged images show that AGT clearly localized in mesangial cells (c) and weakly in glomerular epithelial cells (f). Original magnification: $\times 400$. (D) Comparison of glomerular 4-HNE expression levels between ZDF lean rats and ZDF obese rats at week 18. Representative photomicrographs of immunoreactivity for glomerular 4-HNE in ZDF lean rats and ZDF obese rats at week 18. Immunoreactivity for glomerular 4-HNE in ZDF obese rats was remarkably increased compared with that in ZDF lean rats. Original magnification: $\times 200$. (E) Comparison of urinary 8-isoprostane excretion levels between ZDF lean rats and ZDF obese rats at week 18. Urinary excretion levels of 8-isoprostane in ZDF obese rats $(n=6)$ and ZDF lean rats $(n=5)$ at week $18 .{ }^{*} P<0.01$ vs. ZDF lean rats. AGT, angiotensinogen; 4-HNE, 4-hydroxy-2-nonenal; IF, immunofluorescence; IHC, immunohistochemitry; ZDF, Zucker diabetic fatty. A full color version of this figure is available at the Hypertension Research journal online. 
levels were significantly increased from $30 \mathrm{~min}$ after stimulation with $5 \times 10^{-5} \mathrm{M} \mathrm{H}_{2} \mathrm{O}_{2}$. The AGT mRNA level peaked at $60 \mathrm{~min}$. Thereafter, AGT mRNA expression decreased and it returned to the basal level at 240 min (Figure 2a).

Next, the cells were either treated or not treated with $10^{-5}-10^{-4} \mathrm{M}$ $\mathrm{H}_{2} \mathrm{O}_{2}$ for $30 \mathrm{~min}$. The levels of AGT mRNA expression were increased by $\mathrm{H}_{2} \mathrm{O}_{2}$ treatment in a dose-dependent manner (Figure $2 \mathrm{~b}$ ).

To confirm the role of $\mathrm{H}_{2} \mathrm{O}_{2}$ in AGT mRNA upregulation, primary rat mesangial cells were treated for 30 min with $10^{-4} \mathrm{M} \mathrm{H}_{2} \mathrm{O}_{2}$ and $300 \mathrm{U} \mathrm{ml}^{-1}$ catalase at the same time. Catalase treatment completely suppressed the upregulation of AGT mRNA expression by the $\mathrm{H}_{2} \mathrm{O}_{2}$ treatment (Figure $2 \mathrm{c}$ ). In addition, primary rat mesangial cells were treated with $5 \times 10^{-5} \mathrm{M} \mathrm{H}_{2} \mathrm{O}_{2}$ every hour, and the AGT protein level in the supernatants was examined. AGT protein in the supernatants was detectable at $4 \mathrm{~h}$ after $\mathrm{H}_{2} \mathrm{O}_{2}$ stimulation, and it was observed to increase up to $7 \mathrm{~h}$. The $\mathrm{H}_{2} \mathrm{O}_{2}$-induced accumulation of AGT protein in the supernatants was completely suppressed by catalase treatment, in a manner similar to that observed for AGT mRNA expression (Figure 2d).

\section{$\mathrm{H}_{2} \mathrm{O}_{2}$-induced AGT expression through MAPK pathways}

The MAPK pathways were examined to determine the signal transduction pathway for AGT expression. Primary rat mesangial cells were treated with $10^{-4} \mathrm{M} \mathrm{H}_{2} \mathrm{O}_{2}$ and harvested every $5 \mathrm{~min}$ after $\mathrm{H}_{2} \mathrm{O}_{2}$ stimulation. Phosphorylation of ERK, JNK and p38 MAPK was significantly increased from $10 \mathrm{~min}$ after $\mathrm{H}_{2} \mathrm{O}_{2}$ stimulation, and the $\mathrm{H}_{2} \mathrm{O}_{2}$-induced increase in ERK, JNK and p38 MAPK phosphorylation was suppressed by catalase treatment (Figures $3 \mathrm{a}-\mathrm{c}$ ).

Figure 2 (a) Augmentation of AGT mRNA expression by $\mathrm{H}_{2} \mathrm{O}_{2}$ treatment in a time-dependent manner. Primary rat mesangial cells were treated with $5 \times 10^{-5} \mathrm{M} \mathrm{H}_{2} \mathrm{O}_{2}$ for $240 \mathrm{~min}$ ( $n=4$, in each). After the treatment AGT mRNA was measured by qRT-PCR. The levels of AGT mRNA expression were normalized on the basis of $\beta$-actin levels. The data are expressed as relative values compared with the unstimulated control group at 0 min. The filled bars show AGT mRNA expression under unstimulated control conditions and the stippled bars show AGT mRNA expression under stimulation with $\mathrm{H}_{2} \mathrm{O}_{2}$. (b) Augmentation of AGT mRNA expression by $\mathrm{H}_{2} \mathrm{O}_{2}$ treatment in a dosedependent manner. Primary rat mesangial cells were either treated or not treated with $10^{-5}-10^{-4} \mathrm{M} \mathrm{H}_{2} \mathrm{O}_{2}$ for $30 \mathrm{~min}$ ( $n=4$ in each). After the treatment AGT mRNA was measured by qRT-PCR. The levels of AGT mRNA expression were normalized on the basis of $\beta$-actin levels. The data are expressed as relative values compared with the group without $\mathrm{H}_{2} \mathrm{O}_{2}$ treatment $(0 \mathrm{~m}) .{ }^{*} P<0.0001$ vs. $0 \mathrm{~m}$. (c) Effect of catalase treatment on the augmentation of AGT mRNA expression by $\mathrm{H}_{2} \mathrm{O}_{2}$ treatment. $10^{-4} \mathrm{M} \mathrm{H}_{2} \mathrm{O}_{2}$ and $300 \mathrm{U} \mathrm{ml}^{-1}$ catalase were administered to primary rat mesangial cells at the same time and the cells were treated with them for $30 \mathrm{~min}$ ( $n=4$ in each). After the treatment AGT mRNA was measured by qRT-PCR. The levels of AGT mRNA expression were normalized on the basis of $\beta$-actin levels. The data are expressed as relative values compared with the control (column A). The filled bars show AGT mRNA expression under unstimulated conditions with $\mathrm{H}_{2} \mathrm{O}_{2}$ and the stippled bars show AGT mRNA expression under stimulation with $\mathrm{H}_{2} \mathrm{O}_{2}$. ${ }^{*} P<0.0001$ vs. column $\mathrm{A}$; ${ }^{\#} P<0.0001$ vs. column B. (d) Effect of catalase treatment on the augmentation of AGT protein expression in the supernatants by $\mathrm{H}_{2} \mathrm{O}_{2}$ treatment. Primary rat mesangial cells were treated with $5 \times 10^{-5} \mathrm{M} \mathrm{H}_{2} \mathrm{O}_{2}$ and $300 \mathrm{U} \mathrm{ml}^{-1}$ catalase for $7 \mathrm{~h}$ ( $n=3$ in each). $\mathrm{H}_{2} \mathrm{O}_{2}$ was administered every hour. After the treatment the supernatants were concentrated and measured by western blotting. The data are expressed as relative values compared with the 7-h $\mathrm{H}_{2} \mathrm{O}_{2}$ stimulation alone. The stippled bars show AGT protein expression with $\mathrm{H}_{2} \mathrm{O}_{2}$ alone and the hatched bar shows AGT protein expression with coadministration of $\mathrm{H}_{2} \mathrm{O}_{2}$ and catalase. ${ }^{*} P<0.0001$ vs. column E. AGT, angiotensinogen; $\mathrm{H}_{2} \mathrm{O}_{2}$, hydrogen peroxide; qRT-PCR, quantitative real-time RT-PCR.
U0126-a specific MEK inhibitor-suppressed the $\mathrm{H}_{2} \mathrm{O}_{2}$-induced upregulation of AGT mRNA in a dose-dependent manner (Figure 4a). It also suppressed the $\mathrm{H}_{2} \mathrm{O}_{2}$-induced augmentation of AGT protein levels in the supernatants (Figure 4b). These data were also confirmed using another MEK inhibitor, PD98059 (Sigma) (data not shown).
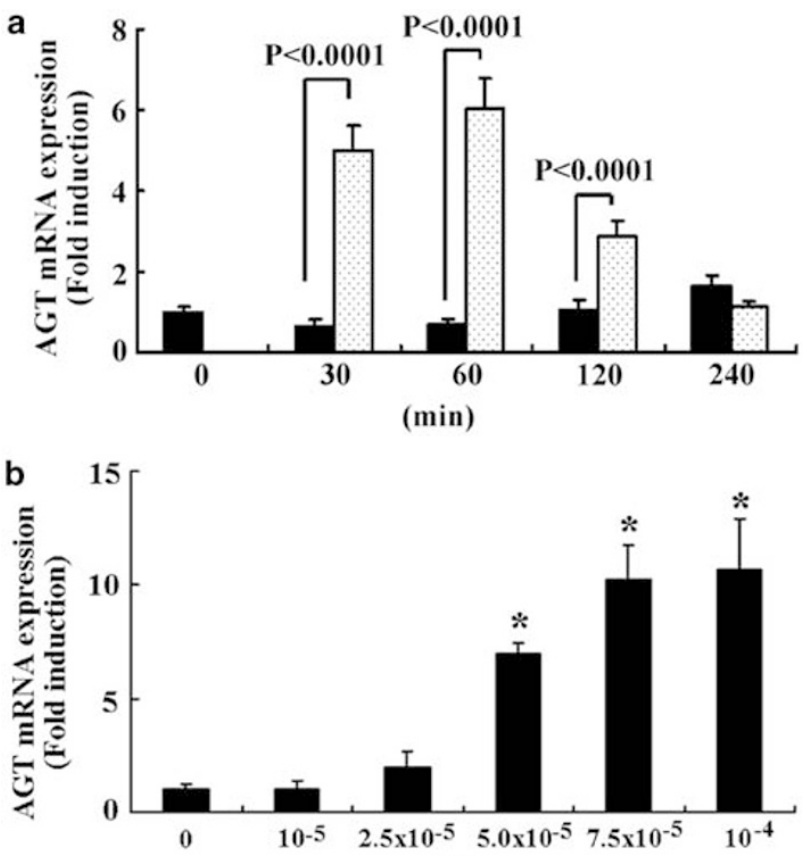

(M)

C

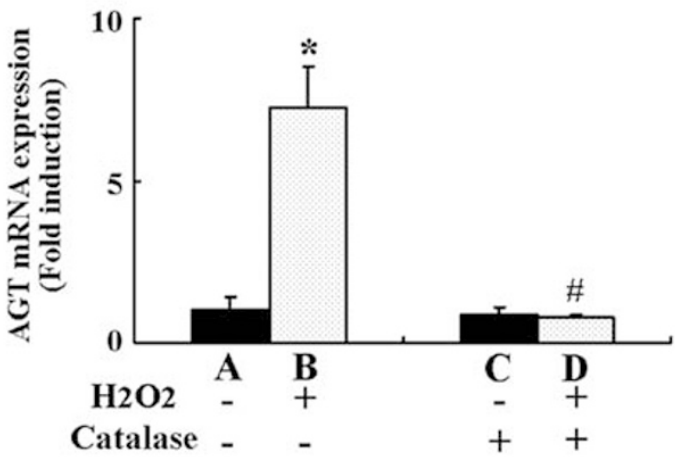

d
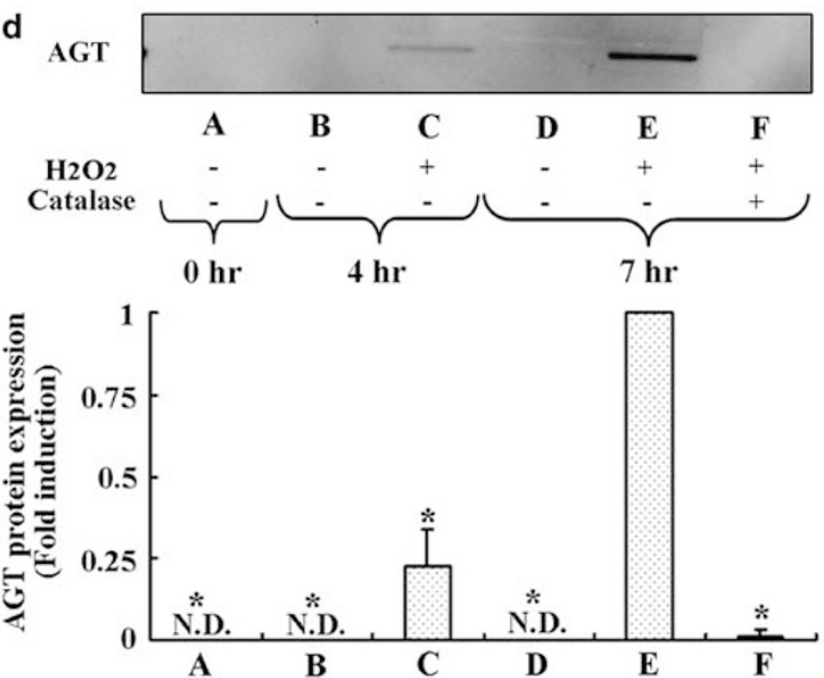
Treatment with a high dose of SP600125-a specific inhibitor of JNK—slightly but significantly suppressed the $\mathrm{H}_{2} \mathrm{O}_{2}$-induced upregulation of AGT mRNA expression (Figure 4c). Similar to AGT mRNA expression, accumulation of AGT protein in the supernatants was

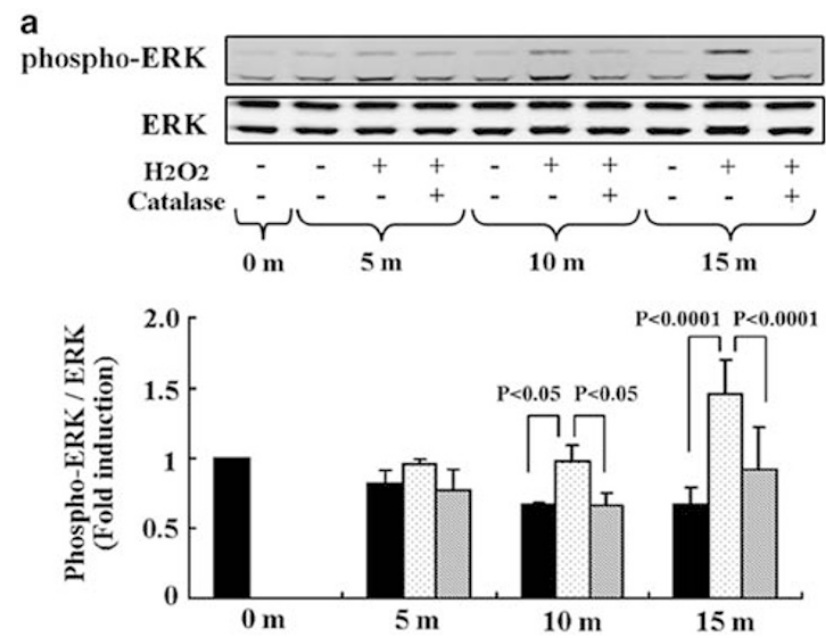

b
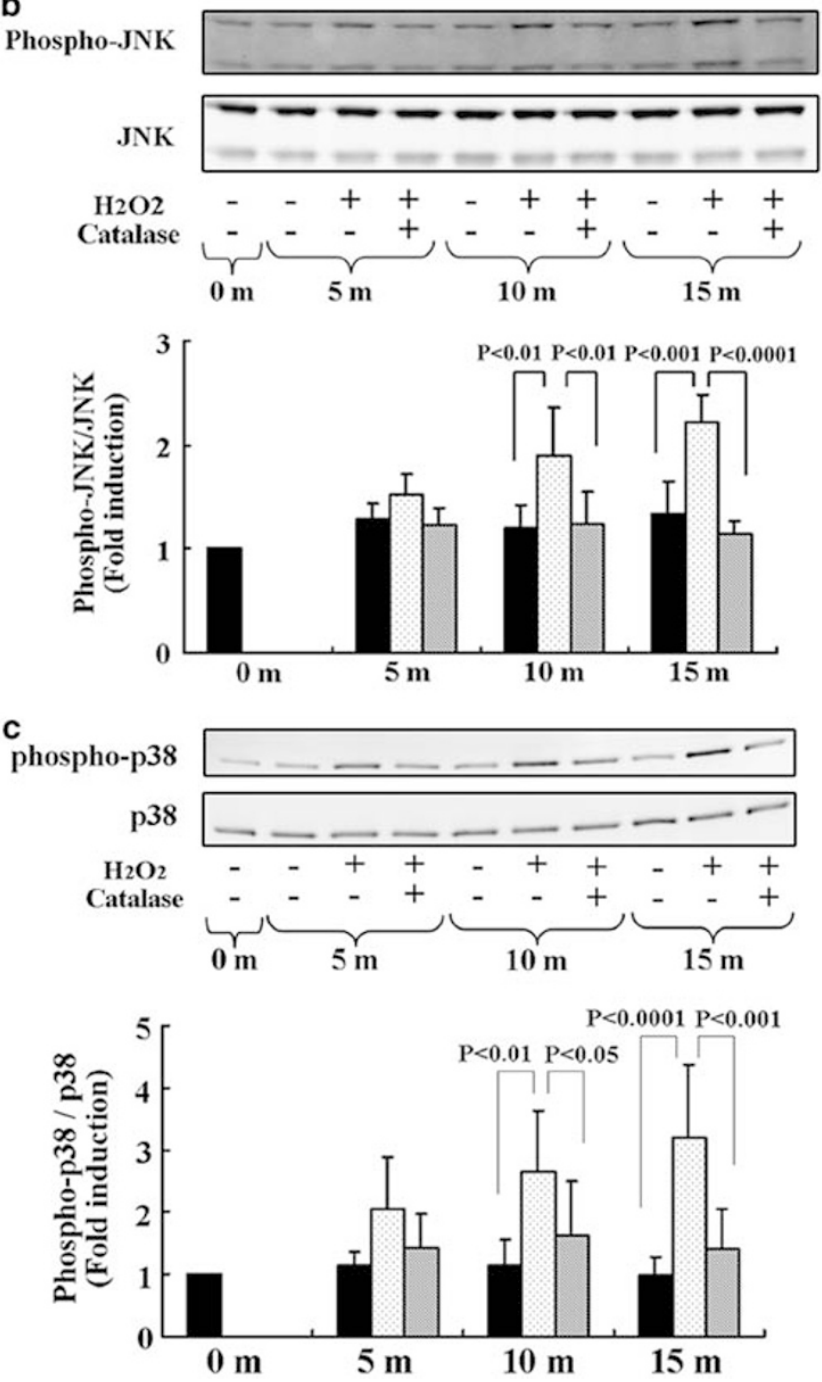

slightly but significantly suppressed by SP600125 treatment (Figure 4d).

Conversely, SB203580 — a specific inhibitor of p38 MAPK—neither inhibited the upregulation of AGT mRNA by $\mathrm{H} 2 \mathrm{O} 2$ treatment (Figure 4e) nor suppressed the accumulation of AGT protein in the supernatants (Figure 4f).

\section{DISCUSSION}

It has been reported that the activated RAS has a role in the development and progression of diabetic nephropathy. ${ }^{15,16,18,19,29}$ For example, in the RENAAL study, it was found that losartan-an Ang-II type-1 receptor blocker-conferred significant renal benefits in 1513 nephropathy patients with type-2 diabetes. ${ }^{29}$ Hsieh et al. ${ }^{18}$ demonstrated the stimulatory action of high glucose on the expression of the AGT gene in immortalized rat proximal tubular cells. In addition, using western blot analysis, we have previously shown that the AGT expression levels were high in the cortex of 18-week-old ZDF obese rats compared with those in the cortex of ZDF lean rats. ${ }^{19}$ Therefore, we used 18-week-old ZDF obese and lean rats in this study; the levels of glomerular AGT were found to be high in ZDF obese rats compared with that in ZDF lean rats.

Hyperglycemia not only generates more ROS but also attenuates antioxidative mechanisms through non-enzymatic glycation of oxidant enzymes. ${ }^{30}$ It has also been reported that high glucose stimulates $\mathrm{H}_{2} \mathrm{O}_{2}$ production by mesangial cells. ${ }^{31}$ Furthermore, overexpression of catalase in gene-targeted animal attenuates intra-renal AGT expression in diabetes. ${ }^{32}$ In the study conducted by Namikoshi et al. ${ }^{33}$ on ZDF obese rats, it was observed that the expression of the mRNA of nicotinamide adenine dinucleotide phosphate (NADPH) oxidase components (p22 phox and p47 phox) was upregulated in the renal cortex. In this animal study, we also showed that the levels of

Figure 3 (a) Augmentation of ERK by $\mathrm{H}_{2} \mathrm{O}_{2}$ treatment. Primary rat mesangial cells were treated with $10^{-4} \mathrm{M} \mathrm{H}_{2} \mathrm{O}_{2}$ and $300 \mathrm{U} \mathrm{ml}^{-1}$ catalase for 15 min ( $n=3$ in each). After the treatment phosphorylated ERK and total ERK were measured by western blotting. The levels of phosphorylated ERK expression were normalized on the basis of the levels of total ERK. The data are expressed as relative values compared with the unstimulated control group at $0 \mathrm{~min}$. The filled bars show phosphorylated ERK fold induction under control conditions. The stippled bars show induction with $\mathrm{H}_{2} \mathrm{O}_{2}$ stimulation alone and the hatched bars show induction with coadministration of $\mathrm{H}_{2} \mathrm{O}_{2}$ and catalase. (b) Augmentation of JNK by $\mathrm{H}_{2} \mathrm{O}_{2}$ treatment. Primary rat mesangial cells were treated with $10^{-4} \mathrm{M} \mathrm{H}_{2} \mathrm{O}_{2}$ and $300 \mathrm{U} \mathrm{ml}^{-1}$ catalase for $15 \mathrm{~min}$ ( $n=3$ in each). After the treatment phosphorylated JNK and total JNK were measured by western blotting. The levels of phosphorylated JNK expression were normalized on the basis of the levels of total JNK. The data are expressed as relative values compared with the unstimulated control group at $0 \mathrm{~min}$. The filled bars show phosphorylated JNK fold induction under control conditions, the stippled bars show induction with $\mathrm{H}_{2} \mathrm{O}_{2}$ stimulation alone and the hatched bars show induction with co-administration of $\mathrm{H}_{2} \mathrm{O}_{2}$ and catalase. (c) Augmentation of p38 MAPK by $\mathrm{H}_{2} \mathrm{O}_{2}$ treatment. Primary rat mesangial cells were treated with $10^{-4} \mathrm{M} \mathrm{H}_{2} \mathrm{O}_{2}$ and $300 \mathrm{U} \mathrm{ml}^{-1}$ catalase for $15 \mathrm{~min}$ ( $n=3$ in each). After the treatment phosphorylated p38 MAPK and total p38 MAPK were measured by western blotting. The levels of phosphorylated p38 MAPK expression were normalized on the basis of the levels of total p38 MAPK. The data are expressed as relative values compared with the unstimulated control group at $0 \mathrm{~min}$. The filled bars show phosphorylated p38 MAPK fold induction under control conditions, the stippled bars show induction with $\mathrm{H}_{2} \mathrm{O}_{2}$ stimulation alone and the hatched bars show induction with coadministration of $\mathrm{H}_{2} \mathrm{O}_{2}$ and catalase. $\mathrm{H}_{2} \mathrm{O}_{2}$, hydrogen peroxide; ERK, extracellular signal-regulated kinase; JNK, c-Jun N-terminal kinase; MAPK, mitogen-activated protein kinase. 
a

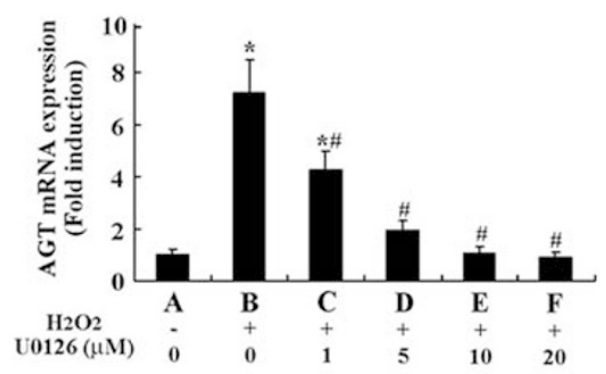

C

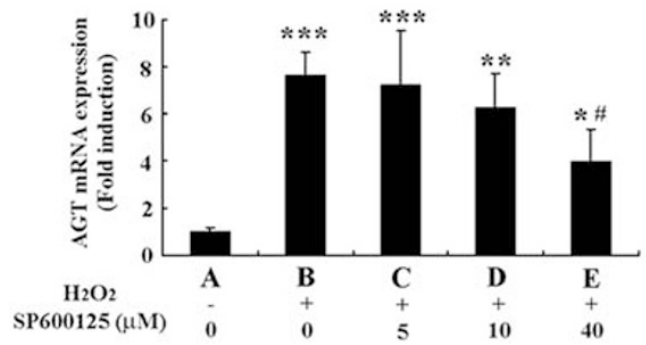

e



b
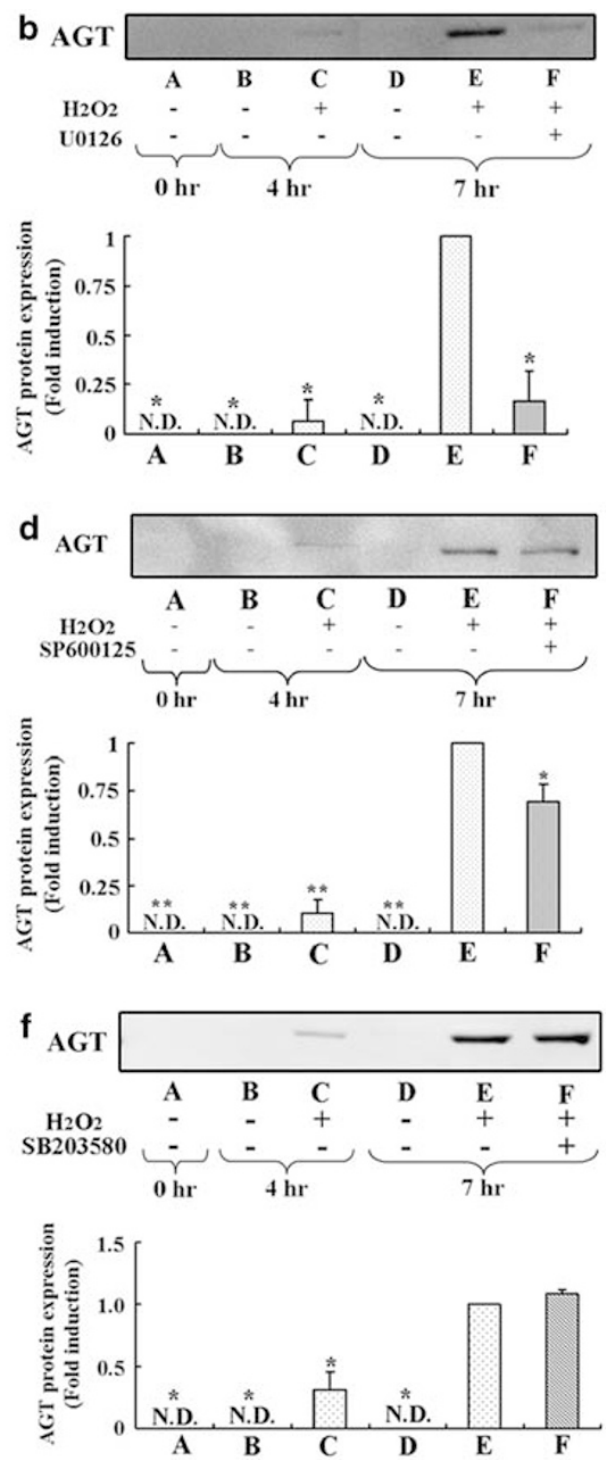

Figure 4 (a) Effect of MAPK kinase (MEK) inhibitor (U0126) on the augmentation of AGT mRNA expression by $\mathrm{H}_{2} \mathrm{O}_{2}$ treatment. Primary rat mesangial cells were treated with $10^{-4} \mathrm{M} \mathrm{H}_{2} \mathrm{O}_{2}$ and an MEK inhibitor (U0126) for $30 \mathrm{~min}$ ( $n=4$ in each). After the treatment AGT mRNA was measured by qRT-PCR. The data are expressed as relative values compared with the control condition (column A). ${ }^{*} P<0.0001$ vs. column $A$; ${ }^{\#} P<0.0001$ vs. column B. (b) Effect of MEK inhibitor (U0126) on the augmentation of AGT protein expression in the supernatants by $\mathrm{H}_{2} \mathrm{O}_{2}$ treatment. Primary rat mesangial cells were treated with $5 \times 10^{-5} \mathrm{M} \mathrm{H}_{2} \mathrm{O}_{2}$ and $10 \mu \mathrm{M}$ MEK inhibitor (U0126) for $7 \mathrm{~h}$ ( $n=3$ in each). $\mathrm{H}_{2} \mathrm{O}_{2}$ was administered every hour. After the treatment the supernatants were concentrated and measured by western blotting. The data are expressed as relative values compared with the 7-h $\mathrm{H}_{2} \mathrm{O}_{2}$ stimulation alone (column $\mathrm{E}$ ). The stippled bars show AGT protein expression with $\mathrm{H}_{2} \mathrm{O}_{2}$ alone and the hatched bar shows AGT protein expression with co-administration of $\mathrm{H}_{2} \mathrm{O}_{2}$ and $\mathrm{UO} 0126$. ${ }^{*} P<0.0001$ vs. column E. (c) Effect of JNK inhibitor (SP600125) on the augmentation of AGT mRNA expression by $\mathrm{H}_{2} \mathrm{O}_{2}$ treatment. Primary rat mesangial cells were treated with $10^{-4} \mathrm{M} \mathrm{H}_{2} \mathrm{O}_{2}$ and an inhibitor of JNK (SP600125) for $30 \mathrm{~min}$ ( $n=4$ in each). After the treatment AGT mRNA was measured by qRTPCR. The data are expressed as relative values compared with the control condition (column A). ${ }^{*} P<0.01$; ${ }^{* *} P<0.001$; ${ }^{* * *} P<0.0001$ vs. column $A$; and ${ }^{\#} P<0.01$ vs. column B. (d) Effect of JNK inhibitor (SP600125) on the augmentation of AGT protein expression in the supernatants by $\mathrm{H}_{2} \mathrm{O}_{2}$ treatment. Primary rat mesangial cells were treated with $5 \times 10^{-5} \mathrm{M} \mathrm{H}_{2} \mathrm{O}_{2}$ and $40 \mu \mathrm{m}$ JNK inhibitor (SP600125) for $7 \mathrm{~h}\left(n=3\right.$ in each). $\mathrm{H}_{2} \mathrm{O}_{2}$ was administered every hour. After the treatment the supernatants were concentrated and measured by western blotting. The data are expressed as relative values compared with the 7-h $\mathrm{H}_{2} \mathrm{O}_{2}$ stimulation alone (column E). The stippled bars show AGT protein expression with $\mathrm{H}_{2} \mathrm{O}_{2}$ alone and the hatched bar shows AGT protein expression with co-administration of $\mathrm{H}_{2} \mathrm{O}_{2}$ and SP600125. ${ }^{*} P<0.001$; ${ }^{* *} P<0.0001$ vs. column E. (e) Effect of p38 MAPK inhibitor (SB203580) on the augmentation of AGT mRNA expression by $\mathrm{H}_{2} \mathrm{O}_{2}$ treatment. Primary rat mesangial cells were treated with $10^{-4} \mathrm{M} \mathrm{H}_{2} \mathrm{O}_{2}$ and an inhibitor of p38 MAPK (SB203580) for $30 \mathrm{~min}$ ( $n=4$ in each). After the treatment AGT mRNA was measured by qRT-PCR. The data are expressed as relative values compared with the control condition (column A). ${ }^{*} P<0.0001$ vs. column A. (f) Effect of p38 MAPK inhibitor (SB203580) on the augmentation of AGT protein expression in the supernatants by $\mathrm{H}_{2} \mathrm{O}_{2}$ treatment. Primary rat mesangial cells were treated with $5 \times 10^{-5} \mathrm{M} \mathrm{H}_{2} \mathrm{O}_{2}$ and $10 \mu \mathrm{M}$ p38 MAPK inhibitor (SB203580) for $7 \mathrm{~h}$ ( $n=3$ in each). $\mathrm{H}_{2} \mathrm{O}_{2}$ was administered every hour. After the treatment the supernatants were concentrated and measured by western blotting. The data are expressed as relative values compared with the 7-h $\mathrm{H}_{2} \mathrm{O}_{2}$ stimulation alone (column E). The stippled bars show AGT protein expression with $\mathrm{H}_{2} \mathrm{O}_{2}$ alone and the hatched bar shows AGT protein expression with co-administration of $\mathrm{H}_{2} \mathrm{O}_{2}$ and $\mathrm{SB203580.}{ }^{*} P<0.0001$ vs. column E. AGT, angiotensinogen; $\mathrm{H}_{2} \mathrm{O}_{2}$, hydrogen peroxide; JNK, c-Jun N-terminal kinase; MAPK, mitogen-activated protein kinase; MEK, MAPK kinase; ND, not detected; qRT-PCR, quantitative real-time RT-PCR. 
glomerular AGT expression, immunoreactivity for 4-HNE in the glomeruli and urinary excretion of 8-isoprostane were increased in ZDF obese rats compared with those in ZDF lean rats. These data suggest that ROS, including $\mathrm{H}_{2} \mathrm{O}_{2}$, upregulates the levels of glomerular AGT expression in ZDF obese rats compared with those in ZDF lean rats. Unfortunately, we did not show whether glomerular AGT expression in ZDF obese rats was suppressed by antioxidant treatment. Furthermore, there is so far no direct evidence to show this. However, we previously showed that an antioxidant, tempol, suppressed the upregulation of intra-renal AGT expression in Dahl-salt-sensitive rats fed on a high-salt diet. ${ }^{34}$ In the future, a study is needed to examine whether an antioxidant treatment suppresses the upregulation of glomerular AGT expression in ZDF obese rats. $\mathrm{H}_{2} \mathrm{O}_{2}$ has the capacity to inhibit the action of tyrosine phosphatases through oxidation of cysteine residues in their catalytic domain, which in turn activates tyrosine kinases and downstream signaling; it is therefore well established that $\mathrm{H}_{2} \mathrm{O}_{2}$ is the main ROS mediating cellular signaling. ${ }^{35,36}$ This is why we used $\mathrm{H}_{2} \mathrm{O}_{2}$ to induce AGT expression in this cell study to elucidate ROS-mediating cellular signaling. In addition to an effect on the transcriptional activation for cellular signaling, $\mathrm{H}_{2} \mathrm{O}_{2}$ is associated with lack of stabilization of some mRNAs. ${ }^{37}$ It is considered that this is why AGT mRNA was increased quickly after $\mathrm{H}_{2} \mathrm{O}_{2}$ administration and decreased rapidly thereafter in this study.

Recently, many investigators have focused on podocytes for research because they not only serve as a filtration barrier against proteins, but also have an important role in the pathogenesis of certain renal diseases. ${ }^{38,39}$ Yoo et al. ${ }^{39}$ reported that the AGT mRNA and protein levels were significantly increased in podocytes cultured under highglucose conditions. Furthermore, using immunohistochemical analysis they showed that the AGT-positive cells within the glomeruli were podocytes and mesangial cells, with a predominance of the former, and that the semi-quantitative staining scores for glomerular AGT were significantly higher in streptozotocin-induced diabetic nephropathy rats than in control rats. In this study, there was some minor staining that was observed in cells other than mesangial cells and there was a possibility that they were localized in podocytes by immunohistochemical double staining. Furthermore, it was confirmed by IF analysis that the levels of glomerular AGT expression were much less in podocytes than in mesangial cells. This discrepancy of AGT expression levels between mesangial cells and podocytes in the glomerulus is probably due to the difference of types in the diabetes mellitus model (streptozotocin-induced diabetes mellitus rat (type-1 diabetes mellitus) versus $\mathrm{ZDF}$ obese rat (type-2 diabetes mellitus)) and/or the difference of methods, including the different anti-AGT antibody. In the near future, a separate study will be performed to examine the stimuli and pathways that induce AGT expression in podocytes.

The pivotal roles of certain MAPK pathways, which are activated by $\mathrm{H}_{2} \mathrm{O}_{2}$ treatment, in certain cell types have been reported. ${ }^{40,41}$ For example, Wang et al. ${ }^{40}$ reported that (1) treating HeLa (human cervical carcinoma) cells with $\mathrm{H}_{2} \mathrm{O}_{2}$ activated ERK, p38 MAPK and JNK; (2) ERK was important for cell survival in the case of oxidant injuries; (3) JNK had a role in the induction of apoptosis and (4) p38 MAPK did not affect the outcome of cell survival. Conversely, Pat et al. ${ }^{41}$ showed that, although $\mathrm{H}_{2} \mathrm{O}_{2}$ stimulation caused the activation of ERK but not JNK in rat renal fibroblasts, it activated both ERK and JNK in rat renal epithelial and endothelial cells. They also showed that activation of ERK in fibroblasts and of JNK in epithelial cells were associated with oxidative stress-induced apoptosis. Furthermore, Hsieh et al. ${ }^{18}$ reported that AGT expression is induced through p38 MAPK expression. Therefore, we have focused on the ROS-MAPK family pathways for AGT expression and clarified that $\mathrm{H}_{2} \mathrm{O}_{2}$ induced
AGT gene expression by the ERK pathway and to a lesser extent by the JNK pathway, but not the p38 MAPK pathway, in this study.

In conclusion, mesangial cells in the glomeruli mainly express AGT under pathological conditions such as diabetic nephropathy. Furthermore, AGT expression in mesangial cells is induced through $\mathrm{H}_{2} \mathrm{O}_{2}$ and the subsequent activation of ERK/JNK, but not p38 MAPK, pathways. These data provide a novel insight into the mechanisms of the activated intra-renal RAS in the development of diabetic nephropathy.

\section{ACKNOWLEDGEMENTS}

This study was supported by grants from the National Institute of Diabetes and Digestive and Kidney Diseases (R01DK072408) and the National Center for Research Resources (P20RR017659). We acknowledge the technical assistance and valuable comments received from Kayoko Miyata, PhD, Toshie Saito, MD, Omar W Acres, BS, Akemi Katsurada, MS, G Michael Upchurch, MS and Nina A Perrault, BS (Tulane University).

1 Paul M, Poyan Mehr A, Kreutz R. Physiology of local renin-angiotensin systems. Physiol Rev 2006; 86: 747-803.

2 Kobori H, Nangaku M, Navar LG, Nishiyama A. The intrarenal renin-angiotensin system: from physiology to the pathobiology of hypertension and kidney disease. Pharmacol Rev 2007; 59: 251-287.

3 Gonzalez-Villalobos RA, Seth DM, Satou R, Horton H, Ohashi N, Miyata K, Katsurada A, Tran DV, Kobori H, Navar LG. Intrarenal angiotensin II and angiotensinogen augmentation in chronic angiotensin II-infused mice. Am J Physiol Renal Physiol 2008; 295: F772-F779.

4 Kobori H, Harrison-Bernard LM, Navar LG. Enhancement of angiotensinogen expression in angiotensin II-dependent hypertension. Hypertension 2001; 37: 1329-1335.

5 Kobori H, Ozawa Y, Suzaki Y, Nishiyama A. Enhanced intrarenal angiotensinogen contributes to early renal injury in spontaneously hypertensive rats. J Am Soc Nephrol 2005; 16: 2073-2080.

6 Navar LG, Harrison-Bernard LM, Imig JD, Wang CT, Cervenka L, Mitchell KD. Intrarenal angiotensin II generation and renal effects of AT1 receptor blockade. J Am Soc Nephrol 1999; 10(Suppl 12): S266-S272.

7 Gould $A B$, Green D. Kinetics of the human renin and human substrate reaction. Cardiovasc Res 1971; 5: 86-89.

8 Darby IA, Congiu M, Fernley RT, Sernia C, Coghlan JP. Cellular and ultrastructural location of angiotensinogen in rat and sheep kidney. Kidney Int 1994; 46: 1557-1560.

9 Darby IA, Sernia C. In situ hybridization and immunohistochemistry of renal angiotensinogen in neonatal and adult rat kidneys. Cell Tissue Res 1995; 281: 197-206.

10 Richoux JP, Cordonnier JL, Bouhnik J, Clauser E, Corvol P, Menard J, Grignon G. Immunocytochemical localization of angiotensinogen in rat liver and kidney. Cell Tissue Res 1983; 233: 439-451.

11 Terada Y, Tomita K, Nonoguchi H, Marumo F. PCR localization of angiotensin II receptor and angiotensinogen mRNAs in rat kidney. Kidney Int 1993; 43: 1251-1259.

12 Kobori H, Harrison-Bernard LM, Navar LG. Expression of angiotensinogen mRNA and protein in angiotensin II-dependent hypertension. J Am Soc Nephrol 2001; 12 : 431-439.

13 Kobori H, Katsurada A, Ozawa Y, Satou R, Miyata K, Hase N, Suzaki Y, Shoji T. Enhanced intrarenal oxidative stress and angiotensinogen in IgA nephropathy patients. Biochem Biophys Res Commun 2007; 358: 156-163.

14 Ingelfinger JR, Jung F, Diamant D, Haveran L, Lee E, Brem A, Tang SS. Rat proximal tubule cell line transformed with origin-defective SV4O DNA: autocrine ANG II feedback. Am J Physiol 1999; 276: F218-F227.

15 Singh R, Singh AK, Alavi N, Leehey DJ. Mechanism of increased angiotensin II levels in glomerular mesangial cells cultured in high glucose. J Am Soc Nephrol 2003; 14: 873-880.

16 Vidotti DB, Casarini DE, Cristovam PC, Leite CA, Schor N, Boim MA. High glucose concentration stimulates intracellular renin activity and angiotensin II generation in rat mesangial cells. Am J Physiol Renal Physiol 2004; 286: F1039-F1045.

17 Satou R, Gonzalez-Villalobos RA, Miyata K, Ohashi N, Katsurada A, Navar LG, Kobori $\mathrm{H}$. Costimulation with angiotensin II and interleukin 6 augments angiotensinogen expression in cultured human renal proximal tubular cells. Am J Physiol Renal Physiol 2008; 295: F283-F289.

18 Hsieh TJ, Zhang SL, Filep JG, Tang SS, Ingelfinger JR, Chan JS. High glucose stimulates angiotensinogen gene expression via reactive oxygen species generation in rat kidney proximal tubular cells. Endocrinology 2002; 143: 2975-2985.

19 Miyata K, Ohashi N, Suzaki Y, Katsurada A, Kobori H. Sequential activation of the reactive oxygen species/angiotensinogen/renin-angiotensin system axis in renal injury of type 2 diabetic rats. Clin Exp Pharmacol Physiol 2008; 35: 922-927.

20 Kagami S, Urushihara M, Kitamura A, Kondo S, Hisayama T, Kitamura M, Loster K, Reutter W, Kuroda Y. PDGF-BB enhances alpha1beta1 integrin-mediated activation of the ERK/AP-1 pathway involved in collagen matrix remodeling by rat mesangial cells. J Cell Physiol 2004; 198: 470-478. 
21 Ohashi N, Yamamoto T, Huang Y, Misaki T, Fukasawa H, Suzuki H, Togawa A, Suzuki S, Fujigaki Y, Nakagawa T, Nakamura Y, Suzuki F, Kitagawa M, Hishida A. Intrarenal RAS activity and urinary angiotensinogen excretion in anti-thymocyte serum nephritis rats. Am J Physiol Renal Physiol 2008; 295: 1512-1518.

22 Urushihara M, Takamatsu M, Shimizu M, Kondo S, Kinoshita Y, Suga K, Kitamura A, Matsuura S, Yoshizumi M, Tamaki T, Kawachi H, Kagami S. ERK5 activation enhances mesangial cell viability and collagen matrix accumulation in rat progressive glomerulonephritis. Am J Physiol Renal Physiol 2010; 298: 167-176.

23 Yoon SW, Chun JS, Sung MH, Kim JY, Poo H. Alpha-MSH inhibits TNF-alpha-induced matrix metalloproteinase-13 expression by modulating p38 kinase and nuclear factor kappaB signaling in human chondrosarcoma HTB-94 cells. Osteoarthritis Cartilage 2008; 16: 115-124.

24 Ohashi N, Katsurada A, Miyata K, Satou R, Saito T, Urushihara M, Kobori H. Role of activated intrarenal reactive oxygen species and renin-angiotensin system in IgA nephropathy model mice. Clin Exp Pharmacol Physiol 2009; 36: 750-755.

$25 \mathrm{Ji} \mathrm{C}$, Kozak KR, Marnett LJ. IkappaB kinase, a molecular target for inhibition by 4-hydroxy-2-nonenal. J Biol Chem 2001; 276: 18223-18228.

26 Patrono C, FitzGerald GA. Isoprostanes: potential markers of oxidant stress in atherothrombotic disease. Arterioscler Thromb Vasc Biol 1997; 17: 2309-2315.

27 Montero A, Munger KA, Khan RZ, Valdivielso JM, Morrow JD, Guash A, Ziyadeh FN, Badr KF. F2-isoprostanes mediate high glucose-induced TGF-beta synthesis and glomerular proteinuria in experimental type I diabetes. Kidney Int 2000; 58: 1963-1972.

28 Yanagawa N, Capparelli AW, Jo OD, Friedal A, Barrett JD, Eggena P. Production of angiotensinogen and renin-like activity by rabbit proximal tubular cells in culture. Kidney Int 1991; 39: 938-941.

29 Brenner BM, Cooper ME, de Zeeuw D, Keane WF, Mitch WE, Parving HH, Remuzzi G, Snapinn SM, Zhang Z, Shahinfar S. Effects of losartan on renal and cardiovascular outcomes in patients with type 2 diabetes and nephropathy. N Engl J Med 2001; 345: 861-869
30 Wolff SP, Jiang ZY, Hunt JV. Protein glycation and oxidative stress in diabetes mellitus and ageing. Free Radic Biol Med 1991; 10: 339-352.

31 Ruiz Muñoz LM, Vidal-Vanaclocha F, Lampreabe I. Enalaprilat inhibits hydrogen peroxide production by murine mesangial cells exposed to high glucose concentrations. Nephrol Dial Transplant 1997; 12: 456-464.

32 Brezniceanu ML, Liu F, Wei CC, Tran S, Sachetelli S, Zhang SL, Guo DF, Filep JG, Ingelfinger JR, Chan JS. Catalase overexpression attenuates angiotensinogen expression and apoptosis in diabetic mice. Kidney Int 2007; 71: 1199-1202.

33 Namikoshi T, Tomita N, Satoh M, Haruna Y, Kobayashi S, Komai N, Sasaki T, Kashihara $\mathrm{N}$. Olmesartan ameliorates renovascular injury and oxidative stress in Zucker obese rats enhanced by dietary protein. Am J Hypertens 2007; 20: 1085-1091.

34 Kobori $\mathrm{H}$, Nishiyama A. Effects of tempol on renal angiotensinogen production in Dahl salt-sensitive rats. Biochem Biophys Res Commun 2004; 12: 746-750.

35 Aslan M, Ozben T. Oxidants in receptor tyrosine kinase signal transduction pathways. Antioxid Redox Signal 2003; 5: 781-788.

36 Tonks NK. Redox redux: revisiting PTPs and the control of cell signaling. Cell 2005; 121: 667-670.

37 Josse C, Boelaert JR, Best-Belpomme M, Piette J. Importance of post-transcriptional regulation of chemokine genes by oxidative stress. Biochem J 2001; 360: 321-333.

38 Barisoni L, Mundel P. Podocyte biology and the emerging understanding of podocyte diseases. Am J Nephrol 2003; 23: 353-360.

39 Yoo TH, Li JJ, Kim JJ, Jung DS, Kwak SJ, Ryu DR, Choi HY, Kim JS, Kim HJ, Han SH, Lee JE, Han DS, Kang SW. Activation of the renin-angiotensin system within podocytes in diabetes. Kidney Int 2007; 71: 1019-1027.

40 Wang X, Martindale JL, Liu Y, Holbrook NJ. The cellular response to oxidative stress: influences of mitogen-activated protein kinase signaling pathways on cell survival. Biochem J 1998; 333(Part 2): 291-300.

41 Pat BK, Cuttle L, Watters D, Yang T, Johnson DW, Gobe GC. Fibrogenic stresses activate different mitogen-activated protein kinase pathways in renal epithelial, endothelial or fibroblast cell populations. Nephrology (Carlton) 2003; 8: 196-204. 